\title{
Implementing Co-Creation And Multiple Intelligence Practices To Transform The Classroom Experience
}

\author{
Stefanie D. Wilson, University of Hawaii - West Oahu, Hawaii
}

\begin{abstract}
Co-creating with a diverse population of learners to enhance their educational experience requires apt skills, namely, multiple intelligence practices. Through the lens of adult learning theories to include multiple intelligences developed by Harvard psychologist Howard Gardner, this empirical research study of a classroom scenario examines the relationship between co-creating and multiple intelligences leadership practices and presents examples of positive effects of co-creating and multiple intelligence practices that have transformed the classroom experience. This article integrates the broader literature on adult learning theories to include theories of multiple intelligences and generates new research and insight for current and future educators to implement and transform the classroom experience.
\end{abstract}

Keywords: Multiple Intelligence; Co-Creation; Adult Learning Theories

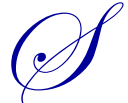

chool systems are witnessing a major paradigm shift, as preparing every student for a digitized world is imperative. Recent advancements in educational technologies such as cloud computing, flipped blended learning, online learning clearly indicates that major academic shifts are underway which impacts how educators teach. A plethora of adult learning theories to include behaviorism, cognitive constructivism, social constructivism, humanism, motivation, intelligence and andragogy have been widely researched and given critical thought and emphasis on boosting human performance in organizations such as educational institutions in the $21^{\text {st }}$ century (Papa, 2011). Co-creation, defined as "the collaborative generation of knowledge by academics working alongside stakeholders" is also examined as a viable approach to address the call to action to transform classroom experiences (Greenhalgh, Jackson, Shaw, \& Janamian, 2016, p. 393).

\section{Adult Learning Theories}

During the early to late $20^{\text {th }}$ century adult learning theories which focused on how adults learn were prevalent and provided insight regarding the process of learning. Several adult learning theories focused on the inborn dissimilarities of the learner, whereas other adult learning theories focused the motivational or behavioral aspects of the learner. An understanding of several adult learning theories is a starting point to: (a) discern how adult learners construct knowledge, (b) use as a guide to assist others with learning, and (c) develop and implement strategies to transform the classroom experience.

\section{Behaviorism or Behaviorist Theory}

Behaviorism involves the learner's positive or negative response to a stimulus which is an integral aspect of the learning process. The behaviorist theory includes the contributions of Locke, Watson, Pavlov and Skinner (Allen \& Whalley, 2011). Their work which focused on the study of objective behavior defined learning based on operant conditioning. Operant conditioning is a process whereby learners construct knowledge based on prior knowledge, and change their behavior based on positive or negative reinforcement. 


\section{Cognitive Constructivism or Cognitive Developmental Theory}

Cognitive constructivism reinforces the notion that stimuli causing an imbalance is constantly being received from the environment, as individuals are involved in varied situations which challenge learners to develop and mature their thought process to maintain equilibrium. The cognitive developmental theory includes the work of Piaget and Bruner. Their work which focused on the cognitive developmental theory or the study of the development and maturation of thinking, viewed knowledge constructed by individuals based on experiences and previously learned knowledge. Piaget's work entailed four stages of cognitive development, of which during the fourth stage, adult cognition and conceptual reasoning abilities occur (Papa, 2011). Based on Piaget's work, Bruner describes the enactive, iconic and symbolic stages of cognitive development that enable individuals to make sense of their world.

\section{Social Constructivism}

Social constructivism emphasizes the social and cultural environmental demands as integral dimensions of the learning process. The social and cultural dimensions to learning involves the relationship between the learner and social properties, and hence social constructivism is a theory that supports, "co-construction of knowledge which is a more student-centered approach to learning" (Papa, 2011, p.96). Vygotsky proposed the idea that the extent of an individual's cognitive development is shaped by their social and cultural environment. Vygotsky's work entailed an analysis of children as they actively participated in social activities with adults or their peers (Allen \& Whalley, 2011). Furthermore, Vygotsky's zone of proximal development, suggests that more-knowledgeable others should assist others to perform, beyond what they are capable of doing to attain what is required.

\section{Humanism or Human Learning Theory}

Humanism is central to the aspect of learning, as it occurs on a personal level. Focusing on the learner to include their emotions and feelings is significant to the learning process, and a central tenet of the human learning theory. Rogers and Maslow's contributions to the human learning theory support the importance of "personal dignity in learning and the need for experiential learning" (Papa, 2011, p.96). Rogers and Maslow contend that every learner has the freedom to make decisions, and with the appropriate guidance and support can address difficulties such as death, medical illness or a learning deficiency. Rogers suggests that learning should focus on the personal level with emotional, affective and cognitive consideration (Papa, 2011). Maslow believed that humans have a hierarchy of needs as some needs are more basic than others. The hierarchy of needs includes "five categories progressing from basic needs for survival and security, to social needs for belonging and respect, to the complex need for fulfillment" (Manning \& Curtis, 2015, p. 285).

\section{Control Theory of Motivation}

Motivation is instrumental to learning. Learners have choices, as their motivation to learn is paramount to learning. A learner's perceived degree of control, driven by internal or external motivators, effects how success or failure is viewed, hence resulting in motivation to learn or lack thereof. Internal motivators may include challenge or curiosity, whereas external motivators may include performing to obtain a reward or prize. Glasser's Control Theory also known as the Choice Theory of motivation contends that learning is based on the wants of a person during a particular time (Papa, 2011).

\section{Multiple Intelligence}

Learners embody varying degrees of intelligences. Learners may have strengths in some abilities, and, unquestionably embody weaknesses in other abilities. An effective learning process requires critical thought and consideration regarding the approach used to engage and enhance learner's intellect. "Creativity and how we engage the learner are supported by Gardner's theory of multiple intelligence" (Papa, 2011, p.97). Gardner (2011) theorized an original list of seven intelligences, as he expanded the list totaling nine intelligences to date. "The seven intelligences he identified: (a) linguistic, (2) musical, (3) logical-mathematical, (4) spatial, (5) bodily-kinesthetic, (6) interpersonal, and (7) intrapersonal. Later [Gardner] added (8) naturalistic intelligence, and (9) existentialist intelligence" (Hall, Quinn, \& Gollnick, 2017, p.431). Each dimension of intelligence focuses on specific skills developed. However, Gardner argues 
that each dimension of intelligence "rarely operate independently but rather combine to complement each other as individuals develop a range of skills and learn how to address challenges and solve problems" (Allen \& Whalley, 2011, pp. 17-18).

\section{Andragogy}

Adult learning also known as andragogy involves an emphasis on the learner's participation, experiential learning and exploring topics relevant to their personal life or career. Adults yearn for learning that is problem centered, focused on their unique abilities, and requires critical thought and reflection. Furthermore, adult learners love to be given the opportunity to plan their learning. Knowles considered and often called the "founding father of adult learning", suggests that actions taken to analyze, reflect, and evaluate on the adult learner's experience is critical to their growth and learning process (Papa, 2011, p, 97).

\section{RESEARCH QUESTIONS}

The research questions for this empirical research study are as follows:

1. How can thoughtful educators use adult learning theories such as multiple intelligence to address varied needs of adult learners and incorporate student-centered practices to transform the classroom experience in the $21^{\text {st }}$ century?

2. How can educators implement co-creation practices to transform the classroom experience?

This article concludes with examples of how the implementation of co-creation multiple intelligences leadership practices can effectively transform the classroom experience and the resulting implications of positive classroom transformation experiences. The content provided may assist educators with transforming the classroom experience and engender further research and debate regarding the relevance of multiple intelligence and co-creation practices to transform the classroom experiences.

\section{Co-Creation}

Creating value in is indeed a challenge for many organizations. Robbins and Coulter (2016) define value as "the performance characteristics, features, and attributes, and any other aspects of goods and services for which customers are willing to give up resources" (p. 571). This challenge of creating value must be met with success, or an organization's existence may be jeopardized. For organizations such as educational institutions, its vision and mission "defines the core purpose of the organization - why it exists - and often describes its values, goals, and aspirations" (Poatsy \& Martin, 2010, p.69). In a university setting, educators create value by assisting learners with acquiring knowledge and skills and supporting the university in collaborative ways (Gardner, 2011). According to Robbins and Coulter (2016), "collaboration is the teamwork, synergy, and cooperation used by individuals when they seek a common goal. When all partners must work together to achieve goals, collaboration is critically important to the process" (p. 116). For example, educators are often collaborating with adult learners and their university peers on an ongoing basis, by tutoring learners in preparation for exams, providing learners with substantive feedback on course assignments, participating as members on university standing committees to resolve campus issues, or perhaps representing the university with colleagues at community events. Collaboration requires a selfless approach to problem solving. As, Nahavandi (2015) asserts "team members are willing to compromise, cooperate, and collaborate to reach their common purpose" (p. 256).

A collaborative approach invites co-creation. Co-creation is a transformation process whereby individuals' partner to attain a mutual outcome. Co-creation engenders diverse perspectives, participatory learning, synergy, and viable solutions that may not occur individually. Co-creating at an educational institution of higher learning is a dynamic and powerful experience, as positive results happen. A perspective of the implementation of co-creation and multiple intelligence leadership practices to attain educational effectiveness is examined further. 


\section{Leadership and Multiple Intelligences (MI)}

"Intelligence plays a role in the leader-follower-situation equation. Intelligence is defined as the cognitive ability, or the ability to perform mental tasks" (Manning \& Curtis, 2015, p. 47). Harvard psychologist, Howard Gardner's (1999) empirical research on human intelligences, identifies seven original multiple intelligences. Gardner's (1999) original list of seven domains of multiple intelligences include: (a) linguistic intelligence, (b) interpersonal intelligence, (c) intrapersonal intelligence, (d) bodily-kinesthetic intelligence, (e) logical intelligence, (f) musical intelligence, and (d) spatial intelligence (pp. 41-43). "From his perspective, instead of having a single IQ, each of us has a profile of intelligences. Any given person might have one or more of her intelligences highly developed, others average, and still others below average" (Matthews \& Foster, 2014, p. 13).

Of the seven original multiple intelligences, Gardner argued that leaders exhibit several multiple intelligences. Gardner (1999) believed that interpersonal, intrapersonal and linguistic intelligences are embodied by effective leaders. "Linguistic intelligence entails being sensitive to spoken and written language, coupled with learning languages and the ability to use language to attain goals or objectives" (Wilson, 2005, p. 14). Linguistic intelligence is evident in authors. "Interpersonal intelligence is the ability to understand and make distinctions among the feelings, beliefs, intentions, motivations, and desires of others, and, ultimately to effectively communicate and work well with others" (Wilson, 2005, p.14).

Demonstrating interpersonal intelligence is significant for educators as they often interface with others to create opportunities and problem solve on a daily basis. "Intrapersonal intelligence refers to the understanding of one's mental model of self, to include the effective handling of one's own abilities, fears, and desires to guide one's life" (Wilson, 2005, p. 14). Intrapersonal intelligence is seen in people viewed as being wise and embodying a huge dose of self-efficacy.

\section{Relationship Between Multiple Intelligence (MI) and Co-Creation Practices}

Gardner (1999) states that "creators and leaders are remarkably similar. Both groups seek to influence the thoughts and behaviors of other people. Both are, accordingly, engaged in the enterprise of persuasion" (p. 130). Furthermore, a difference between leaders and creators lies in the directness of the influence (Gardner, 1999). For example, teachers may lead directly, by lecturing to and dialoguing with adult learners and thereby seeking to provide a positive atmosphere for continuous learning to bring about critical thought, reflection, and cognitive engagement. As Gardner (1999) concludes, "creators in contrast, lead indirectly, through symbolic products - the works of art, the work of science, or the scientific or academic theories they produce" (p.130). Often times, creators produce effective work, having a positive impact on the creator and other stakeholders. "If such work is effective, it ends up changing the way people behave in art, science, or scholarship and reshaping the stories they tell about who they are and how they go about their work" (Gardner, 1999, p. 130).

\section{Classroom Scenario: Multiple Intelligence Leadership Dimensions and Co-Creation Practices}

Let's consider an observed classroom experience whereby multiple intelligence leadership dimensions and co-creation practices, were demonstrated by a professor and an adult learner. The professor of a strategic management course included in the course syllabus, an assignment, whereby developing a business plan for a hypothetical company was required. The professor communicated directly to the class, designated dates for progress updates on the assignment. During the first of three progress updates, the teacher met directly with each adult learner in the class to receive a progress update which included their input and inquiries regarding the assignment. After receiving an update from several adult learners and listening to their input and inquiries, one adult learner expressed to the teacher a lack of confidence in the ability to develop the business plan assignment, and also communicated that failure to seek guidance was due to embarrassment of exposing skill deficiencies.

Further dialogue between the teacher of the strategic management course and the adult learner centered on understanding the adult learner's talents, interests and strengths, how the adult learner learns best, and what the adult learner needed from the teacher to assist with their success. Subsequent to their dialogue, several leadership dimensions of multiple intelligence and co-creation practices to address the opportunity to positively transform the 
classroom experience occurred. The co-creation practices and leadership dimensions of multiple intelligence, namely interpersonal, intrapersonal, and linguistic intelligences are examined further.

\section{Interpersonal and Intrapersonal (MI) Leadership Domains and Co-Creation Practices: To Build Self-Efficacy and Solidify A Teacher Leader-Adult Learner Relationship}

Muff (2013) states that "most of us are never taught how to consider the viewpoints of others. We are largely unaware of how self-limiting beliefs are formed and transformed" (p. 487). The adult learner's internal locus of motivation was evident to the teacher, when the adult learner communicated that assistance was needed to develop the strategic management business plan. The teacher responded to the student in a humanistic non-biased manner, by listening intently to adult learner's concerns, asking the adult learner pertinent questions to gain a greater insight of their talents, strengths and weakness, and work ethic. Furthermore, in addition to an internal locus of motivation the adult learner's lack of self-efficacy was apparent. The adult learner's lack of confidence was a negative response to the challenging learning process.

To the adult learner unfamiliarity with the process of developing a business plan, poor writing skills, and little to no familiarity with required American Psychological Association (APA) style of writing were perceived challenges and roadblocks to effectively completing the business plan assignment. Operant conditioning based on positive reinforcement was continuously exercised by the teacher which resulted in changing the adult learner's behavior. For example, as an initial step towards developing the adult learner's affective, cognitive and writing skills, the learner was tasked by the teacher and praised for the development of a written action plan. The action plan which included milestones and due dates to develop an effective business plan assignment was discussed during their weekly inperson meetings and via email. The development of the action plan was created by the learner with input and approval from the teacher. Positive reinforcement occurred on a continuous basis, as substantive feedback to adult learner instilled hope and a positive mindset. The co-creation of the written action plan and feedback approach assisted with building and solidifying the teacher to adult learner trusting relationship, coupled with enhancing the adult learner's motivation, process of inquiry, creativity, self-efficacy and decision making.

\section{Linguistic (MI) Leadership Domain and Co-Creation Practices: To Effectively Communicate Feedback}

As the weekly in-person meetings between the teacher and adult learner progressed, the adult learner developed another tool with the guidance of the teacher to assist with communicating periodic feedback regarding the business plan assignment progress. The tool focused on enhancing the adult learner's proficiency of communicating in writing, specifically with a focus on content development, organization, readability, and the appropriate use of APA formatting for the business plan assignment. The adult learner and teacher agreed to the tool's clarity and usefulness and shared the tool with the class to assist other learners enrolled in the course with similar writing deficiencies. During this student-centered learning process, Vygotsky's zone of proximal development manifested. The teacher-to-adult learner and adult learner-to adult learner learning dynamics occurred, as more-knowledgeable others assisted others to perform optimally. The dynamics of the learning communities comprised of teacher to learner, as well as peer-to peer learning had a powerful impact on the learning process which encouraged the learners to invest in their own learning? Furthermore, the adult learner's approach to learning had become more self-directed and experiential, which stimulated the learner's cognitive engagement.

\section{Intrapersonal (MI) Leadership Domain and Co-Creation Practices: To Develop A Solid Business Plan and Self-Reflection}

The adult learner was successful on many fronts, which began with the process of self-reflection and ultimately resulted in the development of a solid business plan assignment required for the strategic management course. The learning process between the teacher and adult learner, began and continued with, encouraging the learner to reflect about self, providing the learner access to support and success, and emphasizing the learner's responsibility for learning new and challenging skills in a safe environment.

The teacher was an inspiration and integral part of the adult learner's success, for believing in the learner throughout the learning process, which involved active participation in a series of experiences requiring reflection, critical 
thought, and effective decision making. As co-creators of several tools to assist with the development of the business plan assignment, the teacher and adult learner were engaged and committed to creating a positive learning environment.

\section{CONCLUSION}

Transforming the classroom to a fun, positive, and challenging learning experience can be a daunting task. However, such a formidable process can be rewarding as well. "It is crucial for students and teachers to take responsibility for education, to allow themselves to become vulnerable, and then to exploit that vulnerability in order to acquire knowledge and skills that may mobilize in the acquisition of understanding" (Gardner, 2011, pp. 262-263). Transforming the classroom experience comprised of adult learners is a dynamic process, requiring the educational leader to provide a classroom environment of mutual trust, caring, integrity and inspiration. Implementing co-creation practices and multiple intelligence leadership dimensions can be an effective and rewarding approach to ensure that responsible learning and generative understandings occur (Gardner, 2011).

\section{AUTHOR BIOGRAPHY}

Dr. Stefanie Denise Wilson is a professor of Business Administration at the University of Hawaii-West Oahu. She earned her Bachelor of Science degree in Business Management from Hampton University, Masters degree in Business Administration with specializations in International Business and Marketing from the University of Miami, and Doctor of Management degree in Organizational Leadership from the University of Phoenix. In addition to teaching, Wilson has always been fascinated with human intelligences, organizational dynamics, and leadership. Her research and publication efforts expand on Howard Gardner's "Theory of Multiple Intelligences" by providing new ways to think about leadership. E-mail: sdwilson@hawaii.edu

\section{REFERENCES}

Allen S. \& Whalley M. (2011). Supporting Pedagogy and Practice in Early Years Settings. Padstow, Cornwall Great Britain. Learning Matters Ltd.

Gardner, H. (1999). Intelligence reframed. New York, NY: Basic Books

Gardner, H. (2011). The unschooled mind: How children think and how schools should teach. New York, NY. Basic Books Greenhalgh, T., Jackson, C., Shaw, S., \& Janamian, T. (2016). Achieving research impact through co-creation in communitybased health services: Literature review and case study. Milbank Quarterly, 94(2), 392-429. Doi:10.111/14680009.12197

Hall, G. E., Quinn, L. F., \& Gollnick, D. M. (2017). Introduction to teaching: Making a difference in student learning. Los Angeles, CA SAGE

Manning, G. \& Curtis, K. (2015). The Art of Leadership (5 ${ }^{\text {th }}$ ed). New York, NY. McGraw-Hill Education

Matthews, D. \& Foster, J. (2014). Beyond intelligence: Secrets for raising happily and productive kids. Toronto, Canada. NASI

Muff, K. (2013). Developing globally responsible leaders in business schools: A vision and transformational practice for the journey ahead. Journal of Management Development, (5)23, 487-504.

Nahavandi, A. (2015). The art and science of leadership. (7 $7^{\text {th }}$ ed.). New York, NY. Pearson Education, Inc.

Papa, R. (2011). Technology leadership for school improvement. Thousand Oaks, CA. SAGE Publications, Inc.

Poatsy, M. A. \& Martin, K. (2010). Better business. Upper Saddle, NJ, Pearson Education, Inc.

Robbins, S. P. \& Coulter, M. (2016). Management. (13 ${ }^{\text {th }}$ ed.). New York, NY. Pearson Education, Inc.

Wilson, S. (2005). The relationship between leadership and domains of multiple intelligences. Ann Arbor, MI. ProQuest Information and Learning Company 